\title{
Analytical Calculation for Predicting the Air Gap Flux Density in Surface-Mounted Permanent Magnet Synchronous Machine
}

\author{
Yan-li Feng ${ }^{\dagger}$ and Cheng-ning Zhang*
}

\begin{abstract}
The research of air gap flux density has a significant effect on predicting and optimizing the structure parameters of electrical machines. In the paper, the air gap coefficient, leakage flux factor and saturation coefficient are first analytically expressed in terms of motor properties and structure parameters. Subsequently, the analytical model of average air gap flux density for surface-mounted permanent magnet synchronous machines is proposed with considering slotting effect and saturation. In order to verify the accuracy of the proposed analytical model, the experiment and finite element analysis (FEA) are used. It shows that the analytical results keep consistency well with the experimental result and FEA results, and the errors between FEA results and analytical results are less than $5 \%$ for SPM with high power. Finally, the analytical model is applied to optimizing the motor structure parameters. The optimal results indicate that the analytical calculation model provides a great potential to the machine design and optimization.
\end{abstract}

Keywords: Air gap flux density, Machine optimization, Saturation coefficient, SPM

\section{Introduction}

More and more surface-mounted permanent magnet (SPM) synchronous machines have been recently applied to electric vehicles, industrial and domestic applications because of advantages of simplicity, high efficiency and quiet operation. Thus, the research on these machines performance is of great significance. The SPM performance including output torque and induction electricity depends on the waveform of the air gap flux density $[1,2]$. Therefore, the research on the air gap flux density is necessary.

In general case, it is complicated to obtain the waveform of air gap flux density in the machine design and optimization. However, it is convenient for the average air gap flux density to predict the machine performance. In relevant literatures, more and more papers use the average air gap flux density in the machine optimization. The literature [3] analyzed two optimization methods to design the SPM, and the air gap flux density was considered as an optimization variable. The literatures $[4,5]$ presented the use of genetic algorithms (GA) and the Taguchi method in optimizing the SPM. GA was applied to optimizing the efficiency of the motor, and the average air gap flux density obtained by a simplified model was considered as one of the constraints. However, the simplified model of air

$\dagger$ Corresponding Author: National Engineering Laboratory for Electric Vehicle/Collaborative Innovation Center of Electric Vehicles in Beijing, Beijing Institute of Technology, Beijing, China. (fengyl1208@163.com)

* National Engineering Laboratory for Electric Vehicle/Collaborative Innovation Center of Electric Vehicles in Beijing, Beijing Institute of Technology, Beijing, China

Received: May 20, 2016; Accepted: December 12, 2016 gap flux density ignored the stator saturation and slotting effect, so the SPM optimization could cause some errors. The literatures [6-8] presented an optimal design method of the permanent magnet synchronous machine with concentrated winding. The flux density of air gap, stator yoke and stator teeth was calculated on the basis of the knowledge of the Maxwell theory and vector potential. The accurate results of the Maxwell method can be obtained because of considering geometrical details and nonlinear effects of iron magnetic materials, but the results of all flux density needed to solve the vector magnetic potential equation and Cramer equation, so the computation is very complicated and time consuming.

All the above methods need to obtain the average air gap flux density to optimize the electrical machine, so it is necessary to research the air gap flux density. At present, the average air gap flux density is mainly obtained by the equivalent magnetic circuit method. The literatures $[9,10]$ presented numerical methods such as finite element analysis (FEA) to study the air gap flux density. The FEA was proposed to analyze the air gap flux density of internal permanent magnet (IPM) machine, and an optimal design method for the rotor parameters was carried out to improve the distribution of air gap flux density [9]; the literature [10] analyzed the relations between the machine structure parameters and air gap flux density using the FEA. However, the paper had not proposed the analytical calculation model of the air gap flux density. The literatures [11-13] analyzed the magnetic characteristics of SPM, and established the analytical model using the magnetic circuit analysis method, which could directly calculate the average air gap flux density and no-load leakage coefficient. However, the accuracy of analytical model is limited 
without considering the saturation effect of iron material.

In order to improve the accuracy and computation efficiency of the average air gap flux density, it is necessary to obtain a new analytical method of the average air gap flux density. The paper presents an analytical model of the average air gap flux density for SPM with considering the slotting effect and saturation. The slotting effect and saturation are considered by the air gap coefficient, leakage flux factor and saturation coefficient, respectively. The average air gap flux density, no-load air gap flux for each pole and back-EMF could be obtained by the analytical model.

The remainder of the paper is arranged as follows: In Section 2, the theory of air gap coefficient, leakage flux factor, saturation coefficient and average air gap flux density is introduced; In Section 3, a new analytical calculation of average air gap flux density is modeled and the proposed analytical model is validated from FEA and experimental results; The application of analytical model is described in the Section 4; Section 5 concludes this paper.

\section{Basic topology and analytical model}

\subsection{The topology and theory of machine}

In the paper, SPM has been chosen to demonstrate the approach. The simplified topology of SPM is shown in Fig. 1. Given the flux distribution indicated in Fig. 1 and the Ohm' law equivalent of magnetic circuit, the equivalent magnetic circuit is shown in Fig. 2.

The variables of Fig. 2 are defined as follows:

$\varphi_{r}$ is the flux source of one magnet pole, $\varphi_{0}$ is the internal leakage flux for one magnet pole, $\varphi_{\delta}$ is the air gap flux for one magnet pole, $\varphi_{\sigma}$ is the air gap leakage flux for

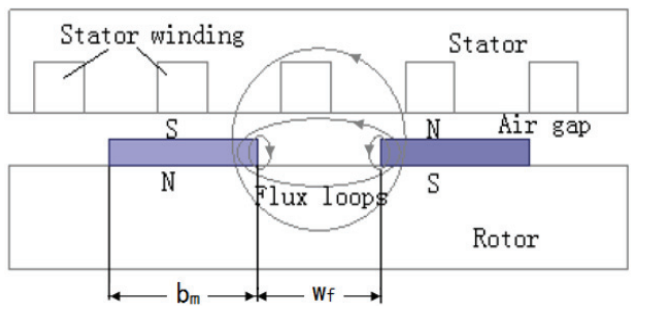

Fig. 1. The topology of SPM

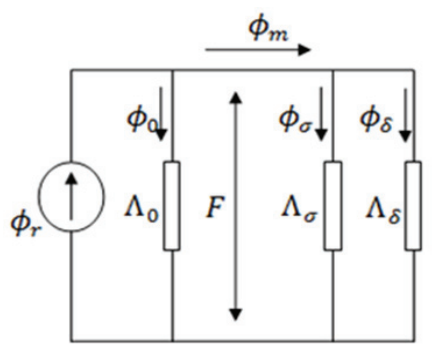

Fig. 2.The equivalent magnetic circuit for Fig. 1 one magnet pole, $\varphi_{m}$ is the total air gap flux for one magnet pole, where $\varphi_{m}=\varphi_{\delta}+\varphi_{\sigma}, \Lambda_{0}$ is the leakage permeance for magnet pole, $\Lambda_{\delta}$ is the permeance for air gap and stator, $\Lambda_{\sigma}$ is the leakage permeance for air gap, $F$ is the magnetomotive force for one magnet pole.

From Fig. 2, we can obtain:

$$
\left\{\begin{array}{l}
F=H h_{m} \\
\sigma \varphi_{\delta}=\varphi_{m}
\end{array}\right.
$$

where, $H$ is the magnetic field strength for one magnet pole, $h_{m}$ is magnet thickness and $\sigma$ is air gap leakage flux factor.

Assume $F_{\delta}$ is the air gap magnetomotive force for one magnet pole, the Eq. (1) can be given by

$$
\left\{\begin{array}{l}
F_{\delta}=H_{\delta} k_{\delta} \delta \\
k_{s} F_{\delta}=H h_{m} \\
\sigma \alpha_{i} B_{\delta} \tau\left(L_{a}+2 \delta\right)=B S_{m}
\end{array}\right.
$$

where, $H_{\delta}$ is the air gap magnetic field strength, $k_{\delta}$ is the air gap coefficient, $k_{s}$ is the stator saturation coefficient, $\alpha_{i}$ is the effective pole arc coefficient, $\tau$ is the pole pitch, $B_{\delta}$ is the average air gap flux density, $L_{a}$ is the machine axial length, $\delta$ is the air gap length, $S_{m}$ is the magnet area and $B$ is the flux density for permanent magnet.

Because the permanent magnet material of SPM is the rare-earth and the rare-earth has a straight demagnetization curve, the value of $H$ is defined by

$$
H=\frac{B_{r}-B}{\mu_{0} \mu_{r}}
$$

where, $\mu_{0}$ is the air permeability and $\mu_{r}$ is relative permeability of magnet.

Substituting the Eq. (3) into the Eq. (2), the average air gap flux density of SPM is

$$
B_{\delta}=B_{r} \frac{h_{m}}{A \sigma h_{m}+\mu_{r} k_{s} k_{\delta} \delta}
$$

where

$$
A=\frac{D\left(L_{a}+2 \delta\right) \alpha_{i}}{L_{a}\left(D-2 \delta-2 h_{m}\right) \alpha_{p}}
$$

where, $\alpha_{p}$ is the pole arc coefficient.

\subsection{Air gap coefficient and leakage flux factor}

The air gap coefficient is applied to considering the stator slotting effect [14], which can be expressed by

$$
k_{\delta}=\frac{k_{\delta m}\left(h_{m}+\delta\right)-h_{m}}{\delta}
$$


where

$$
\begin{gathered}
k_{\delta m}=\frac{t}{t-\sigma_{s m} b_{s}} \\
\sigma_{\delta m}=\frac{2}{\pi}\left\{\arctan \left(\frac{b_{s}}{2\left(\delta+h_{m}\right)}\right)-\frac{\delta+h_{m}}{b_{s}} \ln \left[1+\left(\frac{b_{s}}{2\left(\delta+h_{m}\right)}\right)^{2}\right]\right\}
\end{gathered}
$$

where, $k_{\delta m}$ is the Carter's coefficient, $t$ is the slot pitch and $b_{s}$ is the width of slot opening.

\subsection{Air gap leakage flux factor}

The research of air gap leakage flux factor has been widely developed. The equivalent magnetic circuit is one of the most satisfactory techniques to calculate the leakage flux factor. The equivalent magnetic circuit is presented in Fig. 2, and the air gap leakage flux factor can be obtained by magnetic circuit approach [13]. That is,

$$
\sigma=1+\frac{\delta_{e}\left[\frac{4 \delta_{e}}{w_{f}+\delta_{e}}+\frac{4 \delta_{e}}{l_{t}+2 \delta_{e}}+\frac{2}{\pi} \ln \left(1+\frac{\pi \delta_{e}}{h_{m}}\right)\right]}{b_{m}+2 \delta_{e}}+\frac{\frac{2 \delta_{e}}{3 \pi} b_{m} \ln \left(\frac{3 \pi}{2 h_{m}} \delta_{e}+1\right)}{\left(b_{m}+2 \delta_{e}\right)\left(L_{a}+2 \delta_{e}\right)}
$$

where, $w_{f}$ is the distance between magnets, $l_{t}$ is average slot width of air gap within the stator slot and $b_{m}$ is width of one magnet pole.

\subsection{Saturation coefficient}

The saturation of stator iron material has a great effect on stator permeability, thus the air gap flux density is greatly affected by the stator saturation. The saturation of stator yoke is neglected owing to the fact that the magnetic circuit area of stator teeth is much less than that of stator yoke. Therefore, the saturation coefficient is calculated by

$$
k_{s}=1+\frac{F_{t}}{F_{\delta}}=1+\frac{H_{t} h_{t}}{H_{\delta} \delta_{e}}
$$

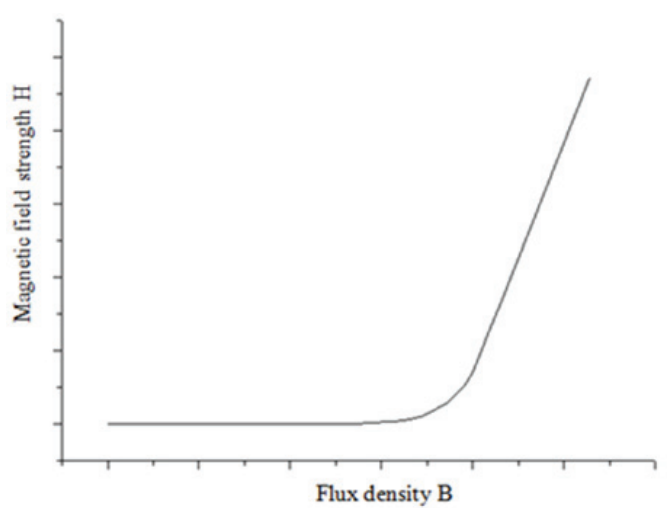

Fig. 3.The basic magnetization curve of iron material where, $H_{t}$ is the magnetic field strength of stator teeth and $h_{t}$ is the effective magnetic circuit length of stator teeth.

The magnetization curve of iron material is shown in Fig. 3. Based on the magnetic data, the fitting expression of magnetization curve can be obtained by curve fitting method. That is,

$$
H_{t}=a_{1} B_{t}+a_{n} B_{t}^{n}
$$

where, $a_{1}, a_{n}, n$ is the coefficient of fitting expression, the value of $n$ is generally higher than 8 .

Similarly, according to the theory that the flux cannot change suddenly, the relation between stator teeth flux density and air gap flux density is given by

$$
B_{t}=\frac{B_{\delta} t L_{a}}{b_{t} K_{F e} L_{a}}
$$

where, $K_{F e}$ is the stacking factor of iron core and $b_{t}$ is the stator teeth width.

Substituting Eq. (11) and (12) into Eq. (10), the saturation coefficient can be easily calculated by

$$
k_{s}=1+\frac{\left[a_{1} \frac{t}{b_{t} K_{F e}}+a_{n}\left(\frac{t}{b_{t} K_{F e}}\right)^{n} B_{\delta}^{n-1}\right] \mu_{0} h_{t}}{\delta_{e}}
$$

\subsection{The analytical model of air gap flux density}

Consequently, Substituting Eqs. (6), (9) and (13) into Eq. (4), the analytical calculation model of the average air gap flux density is

$$
\begin{aligned}
& \left(A \sigma h_{m}+\mu_{r} k_{\delta} \delta+a_{1} C_{t} \mu_{0} \mu_{r} h_{t}\right) B_{\delta}+a_{n} C_{t}^{n} \mu_{0} \mu_{r} h_{t} B_{\delta}{ }^{n} \\
& =B_{r} h_{m}
\end{aligned}
$$

where

$$
C_{t}=\frac{t}{b_{t} K_{F e}}
$$

\section{The New Analytical Calculation Method}

\subsection{The structure and parameters of machine}

In order to obtain the accuracy calculation method of average air gap flux density, the electromagnetic field of SPM is analyzed in this section. The basic machine parameters are listed in Table 1, and the model of machine structure is shown in Fig. 4. In the SPM, a three phase, star-connected, double-layer distributed winding construction is used. The laminated core packs are made of SiFe (DW465-50), and the magnets are formed from the 
Table 1. Motor design parameters

\begin{tabular}{c|c|c}
\hline Items & Motor.1 & Motor.2 \\
\hline Rated power[kW] & 90 & 65 \\
\hline Rated speed[r/min] & 2500 & 2500 \\
\hline Stator outer diameter[mm] & 378 & 310 \\
\hline Stator inner diameter[mm] & 270 & 220 \\
\hline Number of poles & 6 & 4 \\
\hline Number of slots & 54 & 54 \\
\hline Pole arc coefficient & 0.7 & 0.7 \\
\hline Axial length of stator[mm] & 226 & 210 \\
\hline
\end{tabular}

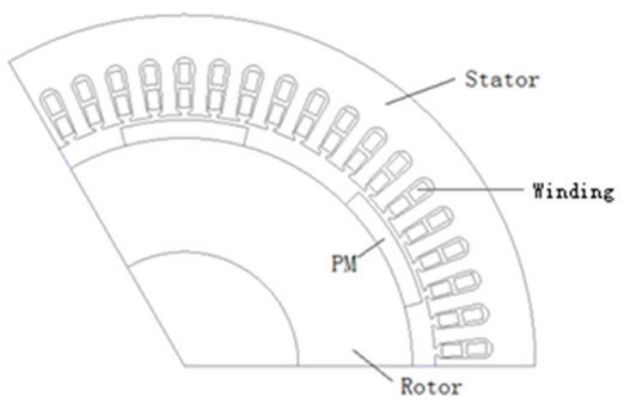

Fig. 4. The analysis model of SPM

rare earth-cobalt (XG208/44) grade with $B_{r}=1.0 \mathrm{~T}$ and $H_{c}$ $=607881 \mathrm{~A} / \mathrm{m}$.

\subsection{The FEA method}

The analysis of electromagnetic field is a complex nonliner and three-dimension problem. However, the energy transfer of machine is produced inside the air gap, and the machine length along the shaft dimension is much longer than the air gap length, thus end-effects are neglected and the analysis of magnetism field may be changed into a two-dimension problem. Therefore, the paper analyses the magnetic field of SPM by two-dimension FEA. In order to reduce the complexity and computation time of FEA, the assumptions are made in the following.

1) The machine end-effects are neglected, and the magnetic field is uniformly distributed in the axial direction. That is, the current density vector and vector magnetism potential only have axial component;

2) Iron core material is isotropy;

3) The hysteresis effect and eddy-current effect of iron core are neglected;

4) The magnetic field in the outer shell of machine is neglected, and the magnetic field of shaft is also neglected.

According to the above assumption, the machine structure shown in Fig. 4 and machine parameters listed in Table 1, the air gap flux density can be obtained by FEA.

Fig. 5 shows the fundamental amplitudes of air gap flux density calculated by FEA for two different machines listed in Table 1. The air gap length varies from $0.2 \mathrm{~mm}$ to $2 \mathrm{~mm}$ when the magnet thickness is $8 \mathrm{~mm}$ and $10 \mathrm{~mm}$ respectively.

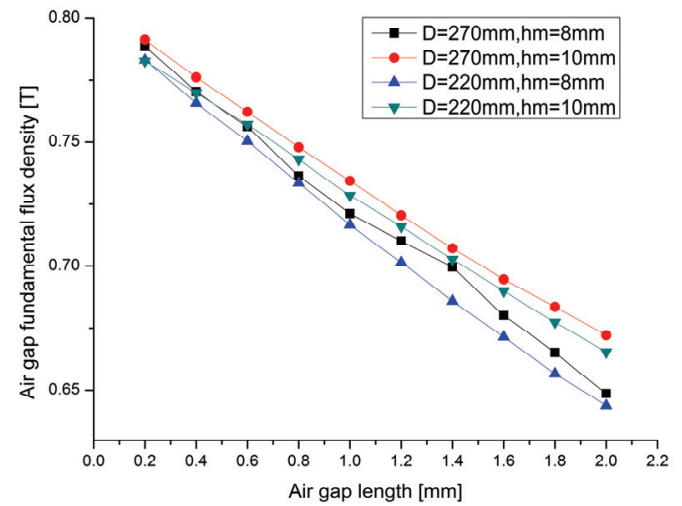

Fig. 5. The air gap flux density when air gap length varies

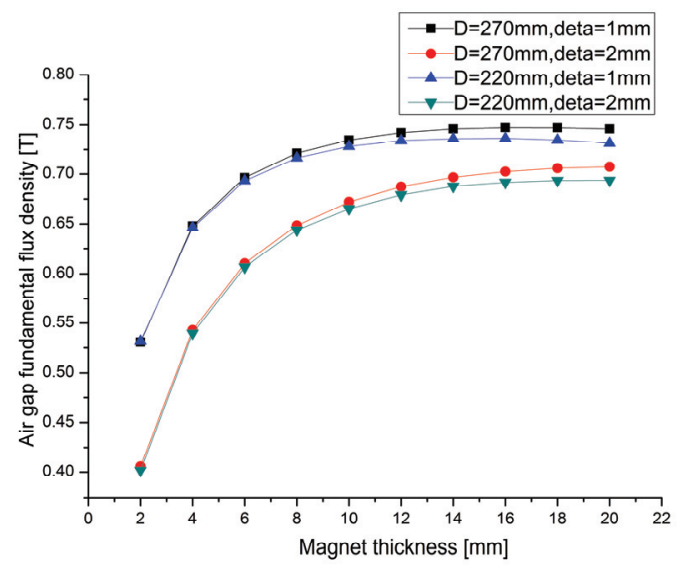

Fig. 6. Air gap flux density when magnet thickness varies

The increase of air gap length will enhance the leakage flux around the end of magnet, and result in the reduction of the average air gap flux density. However, if the air gap length of machine is too small, it may cause difficulties in the process of assembling machine.

Fig. 6 shows the fundamental amplitudes of the air gap flux density calculated by FEA. The magnet thickness varies from $2 \mathrm{~mm}$ to $20 \mathrm{~mm}$, and the air gap length is $1.0 \mathrm{~mm}$ and $2.0 \mathrm{~mm}$ respectively. The air gap flux density should increase in theory when the magnet thickness increases. However, the saturation of stator iron material may restrict the air gap flux density. Therefore, the air gap flux density would reach maximum when the magnet thickness increases to some extent. The extent value of magnet thickness changes with air gap length. Furthermore, the magnet thickness cannot exceed the extent value in the machine design.

Fig. 7 shows the fundamental amplitudes of the air gap flux density when pole arc coefficient varies from 0.5 to 0.95 . The air gap length is $1.0 \mathrm{~mm}$ and $2.0 \mathrm{~mm}$, and magnet thickness is $8 \mathrm{~mm}$ and $12 \mathrm{~mm}$ respectively. The variety of pole arc coefficient will change the magnet volume, and result in the change of air gap flux density. The air gap flux density is enhanced with the increase of pole arc coefficient, and it is hardly changed when the coefficient 
Table 2. The air gap flux density obtained by Eq. (17)

\begin{tabular}{c|c|c|c|c}
\hline \multirow{2}{*}{$\begin{array}{c}\text { Air gap } \\
\text { length }[\mathrm{mm}]\end{array}$} & \multicolumn{2}{|c|}{$h m=8[\mathrm{~mm}]$} & \multicolumn{2}{c}{$h m=10[\mathrm{~mm}]$} \\
\cline { 2 - 5 } & Motor. 1 & Motor. 2 & Motor. 1 & Motor. 2 \\
\hline 0.2 & $0.8969 \mathrm{~T}$ & $0.8849 \mathrm{~T}$ & $0.8899 \mathrm{~T}$ & $0.8742 \mathrm{~T}$ \\
\hline 0.4 & $0.8698 \mathrm{~T}$ & $0.8574 \mathrm{~T}$ & $0.8669 \mathrm{~T}$ & $0.8508 \mathrm{~T}$ \\
\hline 0.6 & $0.8438 \mathrm{~T}$ & $0.8311 \mathrm{~T}$ & $0.8445 \mathrm{~T}$ & $0.8282 \mathrm{~T}$ \\
\hline 0.8 & $0.8190 \mathrm{~T}$ & $0.8059 \mathrm{~T}$ & $0.8229 \mathrm{~T}$ & $0.8063 \mathrm{~T}$ \\
\hline 1.0 & $0.7952 \mathrm{~T}$ & $0.7820 \mathrm{~T}$ & $0.8021 \mathrm{~T}$ & $0.7853 \mathrm{~T}$ \\
\hline 1.2 & $0.7724 \mathrm{~T}$ & $0.7591 \mathrm{~T}$ & $0.7819 \mathrm{~T}$ & $0.7652 \mathrm{~T}$ \\
\hline 1.4 & $0.7506 \mathrm{~T}$ & $0.7374 \mathrm{~T}$ & $0.7625 \mathrm{~T}$ & $0.7458 \mathrm{~T}$ \\
\hline 1.6 & $0.7298 \mathrm{~T}$ & $0.7167 \mathrm{~T}$ & $0.7438 \mathrm{~T}$ & $0.7272 \mathrm{~T}$ \\
\hline 1.8 & $0.7099 \mathrm{~T}$ & $0.6970 \mathrm{~T}$ & $0.7527 \mathrm{~T}$ & $0.7069 \mathrm{~T}$ \\
\hline 2.0 & $0.6909 \mathrm{~T}$ & $0.6782 \mathrm{~T}$ & $0.6916 \mathrm{~T}$ & $0.6922 \mathrm{~T}$ \\
\hline
\end{tabular}

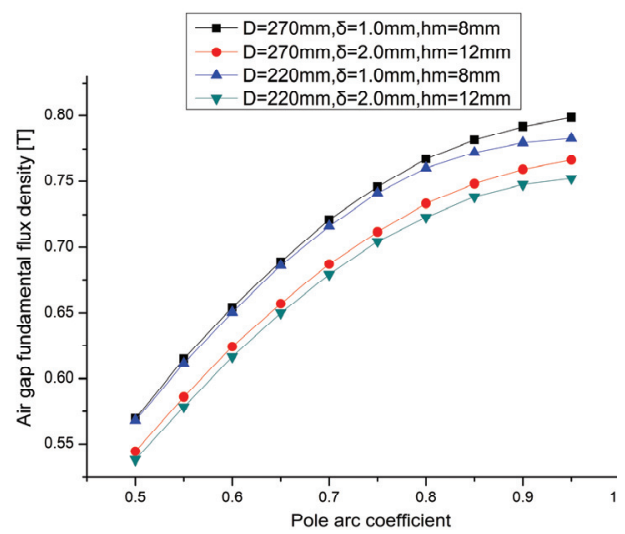

Fig. 7. Air gap flux density when pole arc coefficient varies

increased to some extent.

\subsection{Modify the analytical calculation method}

The stator magnetization curve fitting expression of DW465-50 can be obtained by

$$
H_{t}=100 B_{t}+80 B_{t}^{9}
$$

From the Eq. (14), the relations between the air gap flux density and motor structure parameters can be easily found. Substituting Eq. (16) into Eq. (14), the air gap flux density can be easily calculated by

$$
\begin{aligned}
& \left(A \sigma h_{m}+\mu_{r} k_{\delta} \delta+100 C_{t} \mu_{0} \mu_{r} h_{t}\right) B_{\delta}+80 C_{t}^{9} \mu_{0} \mu_{r} h_{t} B_{\delta}{ }^{9} \\
& =B_{r} h_{m}
\end{aligned}
$$

Based on the machine parameters shown in Table 1 and Eq. (17), the fundamental amplitudes of air gap flux density is listed in Table 2 when the air gap length is $0.2 \mathrm{~mm}$ to $2 \mathrm{~mm}$ respectively. Table 3 shows the air gap flux density when the magnet thickness varies from $2 \mathrm{~mm}$ to $20 \mathrm{~mm}$.

Because the analysis of air gap coefficient, air gap leakage flux factor and saturation coefficient would cause errors in calculating the air gap flux density, it will produce
Table 3. The air gap flux density obtained by Eq. (17)

\begin{tabular}{c|c|c|c|c}
\hline \multirow{2}{*}{$\begin{array}{c}\text { Magnet } \\
\text { thickness[mm] }\end{array}$} & \multicolumn{2}{|c|}{$\delta=1[\mathrm{~mm}]$} & \multicolumn{2}{c}{$\delta=2[\mathrm{~mm}]$} \\
\cline { 2 - 5 } & Motor.1 & Motor.2 & Motor.1 & Motor.2 \\
\hline 2 & $0.6116 \mathrm{~T}$ & $0.6103 \mathrm{~T}$ & $0.8899 \mathrm{~T}$ & $0.4518 \mathrm{~T}$ \\
\hline 4 & $0.7317 \mathrm{~T}$ & $0.7260 \mathrm{~T}$ & $0.4536 \mathrm{~T}$ & $0.5886 \mathrm{~T}$ \\
\hline 6 & $0.7763 \mathrm{~T}$ & $0.7668 \mathrm{~T}$ & $0.5943 \mathrm{~T}$ & $0.6487 \mathrm{~T}$ \\
\hline 8 & $0.7952 \mathrm{~T}$ & $0.7820 \mathrm{~T}$ & $0.6580 \mathrm{~T}$ & $0.6782 \mathrm{~T}$ \\
\hline 10 & $0.8021 \mathrm{~T}$ & $0.7853 \mathrm{~T}$ & $0.6909 \mathrm{~T}$ & $0.6922 \mathrm{~T}$ \\
\hline 12 & $0.8025 \mathrm{~T}$ & $0.7823 \mathrm{~T}$ & $0.7083 \mathrm{~T}$ & $0.6975 \mathrm{~T}$ \\
\hline 14 & $0.7990 \mathrm{~T}$ & $0.7755 \mathrm{~T}$ & $0.7169 \mathrm{~T}$ & $0.6972 \mathrm{~T}$ \\
\hline 16 & $0.7930 \mathrm{~T}$ & $0.7661 \mathrm{~T}$ & $0.7198 \mathrm{~T}$ & $0.6932 \mathrm{~T}$ \\
\hline 18 & $0.7852 \mathrm{~T}$ & $0.7550 \mathrm{~T}$ & $0.7191 \mathrm{~T}$ & $0.6867 \mathrm{~T}$ \\
\hline 20 & $0.7762 \mathrm{~T}$ & $0.7427 \mathrm{~T}$ & $0.7157 \mathrm{~T}$ & $0.6783 \mathrm{~T}$ \\
\hline
\end{tabular}

errors between the analytical results and FEA results. Compared with the analytical results and FEA results, the authors come to the conclusion that the modifying factor $K_{B}$ relates to air gap length $\delta$, magnet thickness $h_{m}$ and stator inner diameter $D_{a}$. Namely,

$$
k_{B}=a_{0}+a_{1} \delta+a_{2} h_{m}
$$

where

$$
\left\{\begin{array}{l}
a_{0}=0.74-\frac{\left(D_{a}-220\right) \times 0.005}{140} \\
a_{1}=32-\frac{\left(D_{a}-220\right)}{70} \\
a_{2}=5.5-\frac{\left(D_{a}-220\right)}{140}
\end{array}\right.
$$

Consequently, the analytical calculation of average air gap flux density is

$$
\left\{\begin{array}{l}
\left(A \sigma h_{m}+\mu_{r} k_{\delta} \delta+100 C_{t} \mu_{0} \mu_{r} h_{t}\right) B_{\delta}+80 C_{t}^{9} \mu_{0} \mu_{r} h_{t} B_{\delta}{ }^{9}=B_{r} h_{m} \\
B_{\delta a}=k_{B} B_{\delta}
\end{array}\right.
$$

The air gap flux density could be calculated by Eq. (20), and the fundamental amplitude of air gap flux density can be calculated by fourier decomposition of the air gap flux density. That is,

$$
B_{\delta a 1}=\frac{4}{\pi} B_{\delta a} \sin \left(\frac{\alpha_{i} \pi}{2}\right)
$$

Based on the equation (20), the no-load air gap flux for each pole $\varphi_{\delta}$ and back-EMF $E_{0}$ of SPM can be respectively calculated by

$$
\begin{gathered}
\varphi_{\delta}=B_{\delta a} \alpha_{i} \tau L_{e f} \\
E_{0}=4.44 f N K_{d p} \varphi_{\delta}
\end{gathered}
$$

where, $f$ is frequency, $N$ is number of turns per phase and $K_{d p}$ is winding factor. 
Table 4. Motor design parameters

\begin{tabular}{c|c}
\hline Items & Value \\
\hline Rated power[kW] & 450 \\
\hline Stator outer diameter[mm] & 490 \\
\hline Stator inner diameter[mm] & 360 \\
\hline Number of poles & 12 \\
\hline Number of slots & 72 \\
\hline Rated speed[r/min] & 2500 \\
\hline Axial length of stator[mm] & 260 \\
\hline Air gap length[mm] & 14 \\
\hline Magnet thickness[mm] & 16 \\
\hline Pole arc coefficient & 0.7 \\
\hline
\end{tabular}
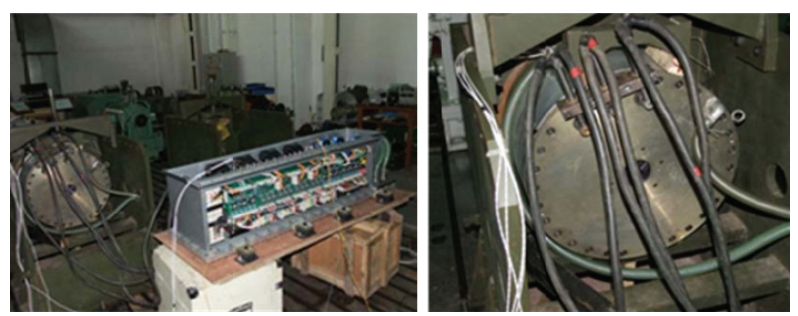

Fig. 8. Experimental implementation

\subsection{FEA and experiment verification}

In order to verify the accuracy of the analytical model for air gap flux density, FEA and experiment method were performed on the SPM with high power. The dimension and parameters of experimental motor are shown in Fig. 8 and Table 4. Magnets are Sm-Co with $\mathrm{Br}=1.05 \mathrm{~T}$ and bulk conductivity $\sigma=1180000 \mathrm{~S} / \mathrm{m}$.

Because it is difficult to obtain the air gap flux density in the experiment, the back-EMF which can be calculated by Eqs. (22) and (23) is measured. The results obtained by analytical calculation, FEA and experiment are listed in Table 5, respectively.

In order to clearly demonstrate the changing trend of verified results, the back-EMF waveform of analytical, FEM and experiment is shown in Fig. 9. From Fig. 9, the analytical results all could keep consistency well with the FEA and experimental results when the magnet thickness changes. It can be seen from Table 5 that the errors between analytical results and FEA results are less than 5\%. In addition, it also illustrates that the back-EMF will increase when the magnet thickness varies from $6 \mathrm{~mm}$ to $20 \mathrm{~mm}$. Therefore, the proposed analytical model is validated.

\section{Application}

It can be seen from the analytical model (20) that the relation between the average air gap flux density and motor structure parameters can be easily found. In addition, the analytical model can be suitable for the optimization of machine structure parameters.
Table 5. The verified results of back-EMF

\begin{tabular}{c|c|c|c|c}
\hline $\begin{array}{c}\text { Magnet } \\
\text { Thickness [mm] }\end{array}$ & $\begin{array}{c}\text { Analytical M } \\
\text { ethod[V] }\end{array}$ & $\begin{array}{c}\text { FEA } \\
{[\mathrm{V}]}\end{array}$ & $\begin{array}{c}\text { Test } \\
{[\mathrm{V}]}\end{array}$ & $\begin{array}{c}\text { Error } \\
{[\%]}\end{array}$ \\
\hline 6 & 185 & 177 & $\backslash$ & 4.32 \\
\hline 8 & 214 & 211 & $\backslash$ & 1.42 \\
\hline 10 & 236 & 238 & $\backslash$ & 0.84 \\
\hline 12 & 252 & 259 & $\backslash$ & 2.70 \\
\hline 14 & 266 & 276 & $\backslash$ & 3.62 \\
\hline 16 & 277 & 289 & 285 & 4.15 \\
\hline 18 & 286 & 300 & $\backslash$ & 4.66 \\
\hline 20 & 294 & 309 & $\backslash$ & 4.85 \\
\hline & & & &
\end{tabular}

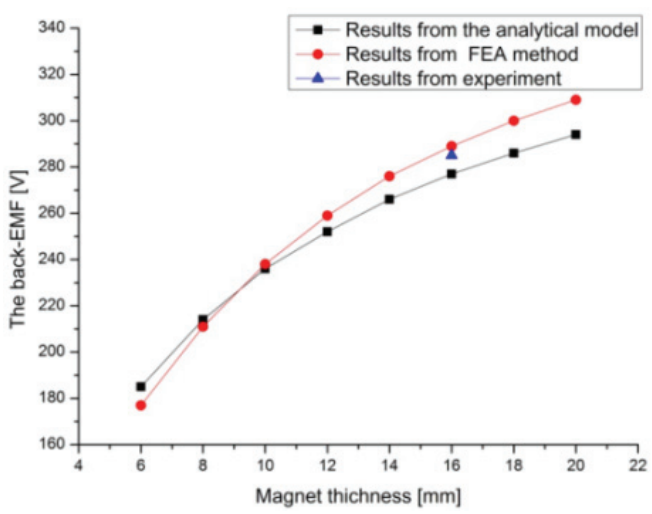

Fig. 9. The back-EMF waveform of verified results

The defined specifications of optimal machine are listed in Table 6. The goal is to design a machine with the high power density. According to the requirement of machine performance, the constraints are established. Table 7 shows the variation ranges of the design variables. The optimization variables, constraints and the objective function are presented as follows:

$$
\left\{\begin{array}{l}
X[14]=\left[D_{a}, \lambda, \lambda_{d}, \delta, h_{m}, \alpha_{p}, b_{s}, \alpha, h_{01}, h_{02}, h_{2}, \lambda_{b}, d_{1}, N_{s}\right] \\
f_{o b j}(x)=\max (P / V) \\
\text { s.t.: } 0.6 \leq B_{\delta} \leq 0.85 \\
1.2 \leq B_{j} \leq 1.6 \\
1.5 \leq B_{t} \leq 1.8 \\
0.7 \leq S_{f} \leq 0.85 \\
6 \leq J \leq 13 \\
230 \leq A_{c} \leq 550 \\
\eta_{N} \geq 0.95
\end{array}\right.
$$

Where, $D_{a}$ is stator inner diameter, $\lambda$ is the ratio between axial length $L_{a}$ and pole pitch, $\lambda_{d}$ is the ratio between stator outer diameter $D_{o}$ and inner diameter, $b_{s}, \alpha, h_{01}, h_{02}, h_{2}, \lambda_{b}$ is stator slot parameters respectively, where $\lambda_{b}=b_{s 2} / h_{2}$. Fig. 10 shows the stator slot. $d_{1}$ is the wire diameter, $P$ is the rated power, $V$ is the machine volume, $B_{\delta}$ is the air gap flux density obtained by analytical model, $B_{j}$ is the flux density of stator yoke, $B_{t}$ is the flux density of stator teeth, $S_{f}$ is the slot fill factor, $J$ is the armature current density, $A_{c}$ is the 
Table 6. The defined specifications of optimal machine

\begin{tabular}{c|c|c|c}
\hline Items & Value & Items & Value \\
\hline Rated power[kW] & 65 & Rated speed[r/min] & 2500 \\
\hline Rated voltage[V] & 300 & Frequency[HZ] & 125 \\
\hline Efficiency[\%] & 95 & & \\
\hline
\end{tabular}

Table 7. The variation ranges of the design variables

\begin{tabular}{c|c|c|c}
\hline Variables & range & Variables & range \\
\hline$D_{a}[\mathrm{~mm}]$ & {$[120,250]$} & $\alpha[\mathrm{deg}]$ & {$[20,45]$} \\
\hline$\lambda$ & {$[0.6,3]$} & $h_{01}[\mathrm{~mm}]$ & {$[0.5,1.5]$} \\
\hline$\lambda_{d}$ & {$[1.2,1.4]$} & $h_{02}[\mathrm{~mm}]$ & {$[1,1.5]$} \\
\hline$\Delta[\mathrm{mm}]$ & {$[0.5,2]$} & $h_{2}[\mathrm{~mm}]$ & {$[10,20]$} \\
\hline$h_{m}[\mathrm{~mm}]$ & {$[4,10]$} & $\lambda_{b}$ & {$[0.25,0.75]$} \\
\hline$\alpha_{p}$ & {$[0.65,0.75]$} & $d_{1}[\mathrm{~mm}]$ & {$[0.5,2]$} \\
\hline$b_{s}[\mathrm{~mm}]$ & {$[2,4]$} & $N_{s}$ & {$[10,20]$} \\
\hline \multicolumn{4}{|c}{}
\end{tabular}

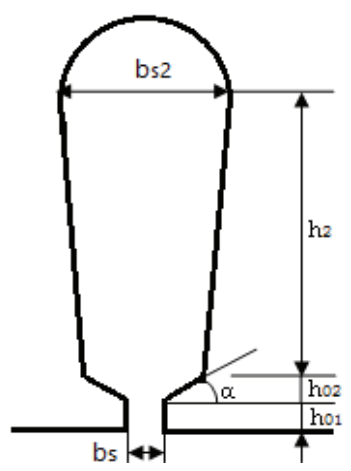

Fig. 10. The stator slot

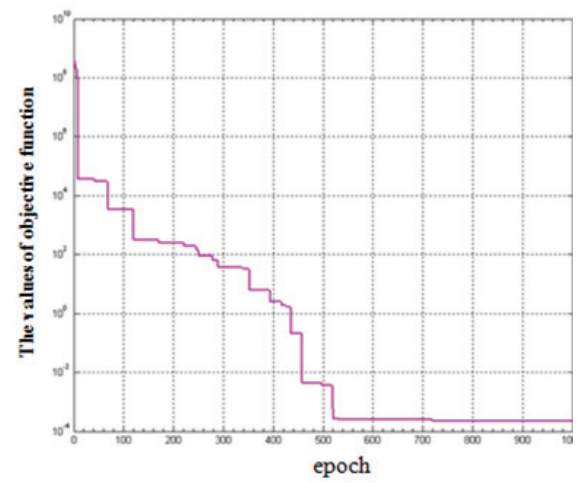

Fig. 11. The optimization process of the objective function

specific electric load, $\eta_{N}$ is the rated efficiency.

According to the objective function, design variables and constraints, the optimization results can be obtained by particle swarm optimization (PSO) technique. Fig. 11 shows the optimization process of the objective function. The objective function receives the optimization results when the epoch is 520. The optimization results of design variables are listed in Table 8 . The air gap flux density can be easily limited in the proper range by the analytical model.

Fig. 12 respectively shows the machine efficiency and torque performance before and after machine optimization.
Table 8. The optimization results of machine

\begin{tabular}{c|c|c}
\hline Design variables & Before optimization & After optimization \\
\hline$D_{a}[\mathrm{~mm}]$ & 220 & 210 \\
\hline$L_{a}[\mathrm{~mm}]$ & 216 & 204 \\
\hline$D_{o}[\mathrm{~mm}]$ & 310 & 290 \\
\hline$\delta[\mathrm{mm}]$ & 1 & 1 \\
\hline$h_{m}[\mathrm{~mm}]$ & 8 & 6 \\
\hline$\alpha_{p}$ & 0.7 & 0.7 \\
\hline$b_{s}[\mathrm{~mm}]$ & 3 & 3 \\
\hline$\alpha[\mathrm{deg}]$ & 34 & 36 \\
\hline$h_{01}[\mathrm{~mm}]$ & 1 & 1 \\
\hline$h_{02}[\mathrm{~mm}]$ & 1.2 & 1 \\
\hline$h_{2}[\mathrm{~mm}]$ & 18.7 & 14 \\
\hline$b_{s 2}[\mathrm{~mm}]$ & 9 & 9 \\
\hline$d_{1}[\mathrm{~mm}]$ & 1.24 & 1.58 \\
\hline$N_{s}$ & 14 & 12 \\
\hline$B_{\delta}[\mathrm{T}]$ & 0.684 & 0.714 \\
\hline$S_{f}$ & $74 \%$ & $76.9 \%$ \\
\hline$\eta$ & $95.6 \%$ & $95.1 \%$ \\
\hline$P_{r}\left[\mathrm{~kW} / \mathrm{m}^{3}\right]$ & 3366 & 4035 \\
\hline & &
\end{tabular}

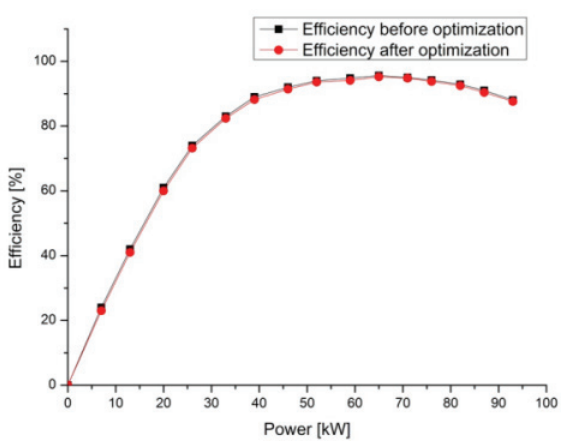

(a) The efficiency

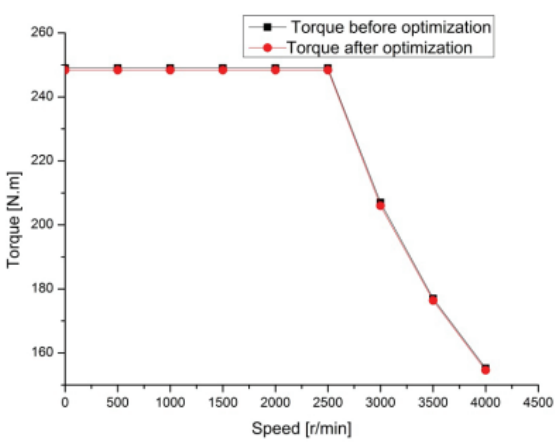

(b) The torque

Fig. 12. The operating performances before and after machine optimization

It can be seen that machine optimization has little effect on the operating performances. However, the machine optimization effectively reduces the machine volume and enhances the power density of machine. The power density is $3366 \mathrm{~kW} / \mathrm{m}^{3}$ before optimization and reaches to 4035 $\mathrm{kW} / \mathrm{m}^{3}$ after optimization. The power density has an obvious improvement after optimization. Therefore, the analytical model of air gap flux density can be applied for 
the machine design and optimization.

\section{Conclusions}

The paper has proposed a new analytical calculation model of average air gap flux density in SPM taking slotting effect, saturation and leakage flux into account. In comparison with the results obtained from the analytical model, experiment and FEA, the main conclusions are put forward as follows:

1) As for different machine structure parameters, the analytical results could keep consistency with the FEA results and experimental results. Therefore, the analytical model could be suitable for directly calculating the air gap flux density of SPM.

2) The analytical model analyses the influence factors for air gap flux density of SPM easily. The relations between air gap flux density and motor structure parameters could be exactly obtained. That is, the air gap flux density drops when air gap length increases. The air gap flux density is enhanced with the increase of magnet thickness, but it has a maximum value because of the saturation of stator iron material.

3) The analytical method could be widely used in the first step of the machine design, and it is helpful for the optimization of machine structure parameters.

4) The machine performance including output torque and back-EMF of SPM depends on air gap flux density. Therefore, based on the fundamental amplitude of air gap flux density, the output torque and back-EMF can be predicted to evaluate the performance of machine.

\section{Acknowledgements}

This work is supported in part by the International Cooperation Research Program of china (2015DFE72810). Meanwhile, it is supported by the National Natural Science Foundation of china (No. 5167070711).

\section{References}

[1] Hwang Chang-Chou, Hung San-Shan, Liu ChengTsung and Cheng Shih-Ping, "Optimal Design of a High Speed SPM Motor for Machine Tool Applications," IEEE Trans. Magn., vol. 90, no. 1, pp. 2478-2481, 2014.

[2] Marco Villani, Giuseppe Fabri, Luca Castellini, "High reliability permanent magnet brushless motor drive for aircraft application," IEEE Trans. Ind. Electron., vol. 59, no. 5, pp. 2073-2081, 2012.

[3] Hejra Msaddek, Stephane Brisset, Ali Mansouri and Hafedh Trabelsi, "Design and optimization of PMSM with outer rotor for electric vehicle," in Proceedings of System,Signal \& Device Conference, 2015.

[4] Hwang Chang-Chou, Lyu Li-Yang, Liu Cheng-Tsung and Li Ping-Lun, "Optimal Design of an SPM Motor Using Genetic Algorithms and Taguchi Method," IEEE Trans. Magn., vol. 44, no. 11, pp. 4325-4328, Nov. 2008.

[5] N. Bianchi and S. Bolognani, "Design optimisation of electric motors by genetic algorithms," in Proceedings of IEE Electr. Power Appl., vol. 145, no. 5, pp. 475-483, Sep. 1998.

[6] H. C. M. Mai, R. Bernard, P. Bigot, F. Dubas, D. Chamagne and C. Espanet, "Optimal design of a PMSM using concentrated winding for application urban hybrid vehicle," Vehicle Power and Propulsion Conference, pp. 1-6, Sep.2010.

[7] Samad Taghipour Boroujeni and Vahid Zamani, "A Novel Analytical Model for No-Load, Slotted, Surface-Mounted PM Machines: Air Gap Flux Density and Cogging Torque," IEEE Trans. Magn., vol. 51, no. 4, Art.ID. 8104008, 2015.

[8] Thierry Lubin, Smail Mezani and Abderrezak Rezzoug, "Two-Dimensional Analytical Calculation of Magnetic Field and Electromagnetic Torque for Surface-Inset Permanent-Magnet Motors," IEEE Trans. Magn., vol. 48, no. 6, pp. 2080-2091, 2012.

[9] Jung-Moo Seo, In-Soung Jung, Hyun-Kyo Jung and Jong-Suk Ro, "Analysis of Overhang Effect for a Surface-Mounted Permanent Magnet Machine Using a Lumped Magnetic Circuit Model," IEEE Trans. Magn., vol. 50, no. 5, Art.ID.8201207, 2014.

[10] Mingji Liu, Zhi Han, Yawei Pei and Pengfei Shi, "Optimization of Permanent Magnet Motor Air gap Flux Density Based on the Non-uniform Air Gap," in Proceedings of IEEE Mechatronic Sciences, Electric Engineering and Computer Conference, pp. 34223426, 2013.

[11] Thierry Lubin, Smail Mezani and Abderrezak Rezzoug, "2-D exact analytical model for surfacemounted permanent magnet motors with semi-closed slots," IEEE Trans. Magn., vol. 47, no. 2, pp. 479-492, 2011.

[12] Ronghai Qu and Thomas A. Lipo, "Analysis and modeling of air-gap and zigzag leakage fluxes in a surface-mounted permanent-magnet machine," IEEE Trans. Ind. Applicat., vol. 40, no. 1, pp. 121-127, 2004.

[13] Bi Liuxin, Wang S and Xia Y., "Calculation of leakage permeance in a surface-mounted permanent magnet machine," Journal of Tsinghua University, vol. 50, no. 4, pp. 525-528, 2010.

[14] Tang Renyuan, "Modern Permanent Magnet Machines," China Mechanical Press, Beijing, China, 2012. 


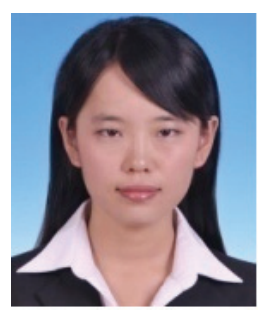

Yan-li Feng She is currently pursuing Ph.D. degree with the Beijing Institute of Technology, Beijing, China. Her research interests are designing and loss analysis of permanent magnet synchronous machines.

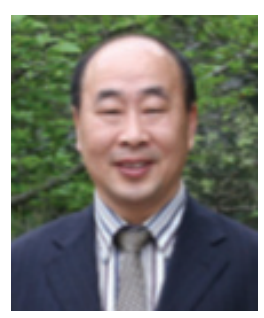

Cheng-ning Zhang $\mathrm{He}$ received the M.E. degree from control theory and control engineering and the Ph.D. degree in vehicle engineering from the Beijing Institute of Technology, Beijing, China, in 1989 and 2001, respectively. $\mathrm{He}$ is currently a Professor and Vice Director of the National Engineering Laboratory for Electric Vehicles, Beijing Institute of Technology. His research interests include electric vehicles, vehicular electric motor drive systems, battery management systems, and chargers. 